\title{
ORIENTASI KONSUMEN, OPORTUNISME KONSUMEN, PERJANJIAN KONTRAKTUAL, KOMITMEN SUMBER DAYA DAN KEMAMPUAN REVERSE LOGISTIC
}

\author{
Amak Mohamad Yaqoub \\ Nurfitri Indriani \\ Fakultas Ekonomi dan Bisnis, Universitas Airlangga \\ Jl. Airlangga No. 4-6, Surabaya 60286 \\ Email: amakyaqoub@yahoo.co.id
}

\begin{abstract}
Abstrak
Penelitian ini bertujuan untuk mengetahui hubungan antara kemampuan reverse logistic dengan orientasi konsumen, oportunisme konsumen, komitmen sumber daya dan perjanjian kontraktual serta menguji hubungan antara kemampuan reverse logistic terhadap penghematan biaya. Data didapatkan melalui kuesioner dan dianalisis menggunakan SmartPLS. Uji menunjukkan tidak terdapat hubungan yang signifikan antara orientasi konsumen dengan kemampuan reverse logistic. Sementara itu, oportunisme konsumen berpengaruh negatif terhadap kemampuan reverse logistic, sedangkan komitmen sumber daya dan perjanjian kontraktual berpengaruh positif terhadap kemampuan reverse logistic. Selain itu, kemampuan reverse logistic memiliki hubungan negatif dengan penghematan biaya.
\end{abstract}

Kata Kunci: Orientasi Konsumen, Oportunisme Konsumen, Perjanjian Kontraktual, Komitmen Sumber Daya, Kemampuan Reverse Logistic

\begin{abstract}
This research aimed to investigate the relationship between reverse logistic capabilities with customer orientation, customer opportunism, resource commitments and contractual arrangements and investigate the relationship between reverse logistic capabilities and cost saving. Data from 30 respondents were collected using questionnaire then analyzed using SmartPLS. Hypotheses testing indicated the absence of relationship between customer orientation and reverse logistic capability. Research also found that resource commitment and contractual arrangement have positive relationship with reverse logistic capability, while negative relationship empirically proven on the relationship between reverse logistic capability and cost saving.
\end{abstract}

Keywords: Customer Orientation, Customer Opportunism, Contractual Arrangement, Resource Commitment, Reverse Logistic Capabilities

\section{PENDAHULUAN}

Reverse logistic telah mendapat perhatian lebih dalam literatur pemasaran dan supply chain (rantai pasok) karena mencerminkan kemampuan perusahaan dalam mengelola saluran distribusi yang dapat memberikan pengaruh positif terhadap pelanggan (Horvath et al., 2005). Studi yang dilakukan oleh Rogers \& Tibben-Lembke (2001), mengungkapkan bahwa biaya reverse logistic dapat menjelaskan ratarata sebanyak empat persen dari total biaya logistik.

Tidak seperti forward logistic, studi tentang reverse logistic masih dalam tahap eksplorasi. Jayaraman \& Luo (2006) mengatakan bahwa perusahaan harus menyadari pentingnya memiliki strategi reverse logistic yang efektif untuk mengurangi risiko merusak hubungan pelanggan yang dapat membahayakan citra merek dan reputasi. Penanganan barang-barang retur, baik dengan cara memindahkan sampah dan material dari lokasi pabrik untuk dibuang ke TPA, dijual atau disumbangkan kepada pihak ketiga (salvage) dan pembuangan sisa bahan (scrap disposal), merupakan bagian dari proses yang berkaitan erat dengan reverse logistic dan juga merupakan komponen supply chain management yang memerlukan perhatian lebih. Apalagi bila pelanggan menuntut kebijakan retur yang lebih fleksibel dan lebih berhubungan dengan proses daur ulang serta lingkungan hidup. Oleh karena itu, perusahaan harus mengetahui betapa pentingnya peran konsumen dalam rantai pasok dan proses reverse logistic.

Reverse logistic saat ini menjadi salah satu alternatif terbaik yang dapat dipertimbangkan untuk mengurangi keterbatasan sumber daya bahan baku. Selain itu, reverse logistic terbukti mampu memberikan nilai ekonomi bagi para pelakunya (Rivera \& 
Ertel, 2008). Reverse logistic meliputi semua aktivitas logistik, namun semua barang yang ditangani mengalir dari arah berlawanan (barang retur). Menangani reverse logistic lebih rumit daripada forward logistic, sebab waktu barang retur mengalir tidak pasti dan sulit diramalkan, datang lebih cepat dibandingkan waktu pemrosesan. Barang retur kebanyakan tidak teridentifikasi dan wewenang penerimaan tidak standar, kondisi barang dan atau kemasan tidak seragam, rusak atau kurang lengkap.

Reverse logistic juga memiliki pengaruh terhadap biaya bagi perusahaan dan pemasoknya (Daugherty et al., 2005). Rumitnya penanganan reverse logistic mengakibatkan membengkaknya biaya operasional (Trebilcock, 2001). Oleh karena itu, perusahaan dituntut untuk memiliki kemampuan reverse logistic (reverse logistic capabilities), yaitu kemampuan internal perusahaan dalam mengelola aktivititas reverse logistic secara lebih efektif untuk mencapai penghematan biaya.

Reverse logistic yang dikelola dengan efisien dan efektif berpotensi mendapatkan nilai ekonomi dan meningkatkan citra positif perusahaan di mata konsumen dan rantai distribusi (Bernon et al., 2004). Nilai ekonomi dari efisiensi reverse logistic didapat melalui pemanfaatan barang retur, diantaranya dengan memakai ulang jika masih dapat dipakai, mendaurulang atau melakukan kanibalisasi untuk bahan baku, perbaikan atau pabrikasi ulang untuk dijual kembali (Stock, 2001). Di samping itu, potensi ekonomi yang tidak langsung adalah penghematan biaya operasional logistik, seperti pengurangan biaya distribusi aliran balik dan pemrosesan atau transaksi (Stock et al., 2002).

Akan tetapi, untuk mencapai tujuan-tujuan di atas, perusahaan harus memperhatikan antecedent (anteseden), yaitu variabel-variabel yang mempengaruhi terbentuknya suatu reverse logistic capabilities atau kemampuan perusahaan dalam mengelola reverse logistic. Variabel-variabel tersebut antara lain adalah customer orientation (orientasi pelanggan), customer opportunism (oportunisme pelanggan), resource commitment (komitmen sumber daya) dan contractual arrangements (perjanjian kontraktual).

Melihat pentingnya faktor-faktor anteseden yang mempengaruhi kemampuan reverse logistic terhadap penghematan biaya pada perusahaan tersebut, maka tujuan dilakukannya penelitian ini adalah untuk mengetahui hubungan antara orientasi pelanggan dengan kemampuan reverse logistic, mengetahui hubungan antara opportunism pelanggan dengan kemampuan reverse logistic, mengetahui hubungan antara peningkatan komitmen sumber daya dengan kemampuan reverse logistic, mengetahui hubungan antara per- janjian kontraktualdengan kemampuan reverse logistic dan mengetahui hubungan antara kemampuan reverse logistic dengan penghematan biaya reverse logistic.

\section{LANDASAN TEORI DAN HIPOTESIS}

\section{Logistik}

Logistik sangat erat kaitannya dengan supply chain management. Logistik lebih menjadi bagian dari supply chain management daripada menjadi bagian tersendiri (Larson et al., 2007). Menurut Bowersox (1990), logistik adalah proses pengaturan strategis pemindahan material, komponen, dan barang siap pakai dari pemasok antar fasilitas dalam perusahaan maupun ke konsumen. Logistik merupakan proses perencanaan, pelaksanaan, dan mengendalikan aliran yang efektif dan efisien dalam biaya bahan baku di dalam proses persediaan, barang jadi, dan informasi yang terkait dari titik asal ke tititk konsumsi untuk tujuan yang sesuai dengan persyaratan pelanggan (Rogers \& Tibben-Lembke, 1999). Logistik lebih menjadi bagian dari supply chain management daripada menjadi bagian tersendiri (Larson et al., 2007).

Kesadaran tentang seni dan pengetahuan akan logistik terus berkembang. Forward logistic sudah bukan merupakan satu-satunya supply chain pada saat ini. Ada penambahan berupa reverse logistic yang juga merupakan supply chain, hanya saja fokus reverse logistic berpusat pada aftermarket supply chain. Ada banyak perbedaan antara forward logistic dan reverse logistic. Krikke (1998) mempertimbangkan beberapa elemen yang membedakan reverse logistic dengan forward logistic diantaranya:

1. Forward logistic menggunakan pull system, sedangkan reverse logistic merupakan kombinasi antara push dan pull.

2. Model yang digunakan forward logistic biasanya berhadapan dengan jaringan-jaringan yang berbeda, sedangkan aliran reverse logistic bisa sangat berbeda atau sama di waktu yang bersamaan

\section{Reverse Logistic}

Reverse logistic merupakan salah satu jenis supply chain yang berkaitan dengan segala jenis kegiatan distribusi dalam aktivitas logistik. Terdapat beberapa definisi reverse logistic ditinjau dari segi proses dan tujuan aktivitasnya. Salah satunya adalah definisi yang disampaikan oleh Rogers \& TibbenLembke (1999). Mereka mendefinisikan reverse logistic sebagai aktivitas untuk merencanakan, mengaplikasikan dan mengendalikan proses agar 
tercapai efisiensi terkait dengan arus material, persediaan, produk jadi dan informasi terkait dari konsumen kembali ke manufaktur dengan tujuan untuk mendapatkan kembali nilai ekonomis produk atau untuk melakukan proses pembuangan yang tepat.

Fleischmann et al. (1997) mendefinisikan reverse logistic sebagai suatu proses yang meliputi kegiatan logistik sepanjang jalan dari produk yang sudah tidak digunakan oleh pengguna untuk dibuat kembali menjadi produk yang bisa digunakan di pasar. Menurut Guide et al. (2000), reverse logistic adalah sebuah cara untuk memperbaiki produk yang gagal, seperti pada pengemasan, pengiriman barangbarang dan pengembalian barang tersebut kepada titik utama pengumpulan untuk didaurulang atau diperbaiki.

Di lain pihak, isu lingkungan menjadi salah satu motivasi terkuat untuk melakukan reverse logistic (Francas \& Minner, 2009; Schulzmann et al., 2006). Meningkatnya tekanan dari berbagai kalangan tentang green-production menjadikan strategi reverse logistic sebagai salah satu strategi utama bagi perusahaan untuk menangani krisis tersebut. Aktivitas utama dari reverse logistic adalah mengumpulkan produk yang akan diperbaharui dan melakukan redistribusi material baru yang dihasilkan (De Brito et al., 2002).

\section{Kemampuan Reverse Logistic (Reverse Logistic Capabilities)}

Penelitian ini berdasarkan pada literatur tentang reverse logistic yang mencakup anteseden dan konsekuensi dari pengembalian suatu produk (Petersen \& Kumar, 2009), proses pengembalian produk (Stock \& Mulki, 2009), mengelola pengembalian produk (Stock et al., 2006) dan mengembangkan program logistik yang efektif (Richey et al., 2005). Penelitian ini tidak hanya menilai hubungan antara retailer (pengecer) dengan pelanggan (business to customer), melainkan juga menilai hubungan antara pengecer dengan perusahaan manufaktur (business to business). Kedua jenis bisnis ini memiliki konsumennya masing-masing.

Business to customer (B2C) menggambarkan hubungan bisnis antara pengecer dengan pelanggan akhir, sedangkan business to business (B2B) menggambarkan transaksi perdagangan antar perusahaan, misalnya perusahaan dengan pengecer. Pengecer maupun perusahaan manufaktur tersebut sama-sama merupakan responden yang menerapkan reverse logistic dan memiliki peran penting dalam mengelola rumitnya proses reverse logistic di dalamnya. Baik pengecer maupun perusahaan manufaktur dituntut untuk mampu mengelola sistem reverse logistic-nya dengan biaya yang serendah mungkin, secara efektif dan efisien, sehingga akan menguntungkan perusahaan secara ekonomi dan dapat meningkatkan citra positif perusahaan.

\section{Anteseden Kemampuan Reverse Logistic}

Anteseden adalah variabel-variabel yang mempengaruhi variabel intervening. Variabel intervening adalah variabel yang secara teoritis mempengaruhi hubungan antara variabel independen dengan variabel dependen menjadi hubungan yang tidak langsung, tidak dapat diamati dan diukur. Dalam penelitian ini, anteseden adalah variabel-variabel yang mempengaruhi terbentuknya kemampuan reverse logistic untuk mencapai penghematan biaya.

Orientasi pelanggan adalah sikap dan perilaku pengecer untuk memberikan kepuasan kepada pelanggan (Deshpande et al., 1993). Sebuah orientasi pelanggan berarti bahwa organisasi dapat mengembangkan keunggulan kompetitif yang berkelanjutan dengan memahami dan memenuhi kebutuhan pelanggan mereka (Deshpande et al., 1993). Berdasarkan konsep pemasaran, orientasi pelanggan harus berdampak positif pada kinerja unit bisnis. Dengan demikian perusahaan yang berorientasi pada pelanggan akan memberikan dampak positif terhadap terbentuknya kemampuan reverse logistic, sehingga hipotesis per-tama adalah:

$\boldsymbol{H}_{\boldsymbol{l}}$ : Terdapat hubungan positif antara orientasi pelanggan dengan kemampuan reverse logistic.

Opportunism pelanggan adalah ketika terjadi sebuah tindakan individu (pelanggan) atau organisasi yang menggunakan suatu hubungan, misalnya hubungan antara pembeli dan penjual untuk kepentingannya sendiri dengan mengorbankan yang lain (Williamson, 1975). Opportunism berlawanan dengan kolaboratif/ hubungan saling percaya (Williamson, 1975). Opportunism merupakan sumber bahaya potensial yang merusak dan melemahkan persepsi terhadap kepercayaan (Williams, 2007). Tingginya tingkat opportunism pelanggan dapat mengakibatkan rendahnya kemampuan reverse logistic suatu perusahaan sehingga dapat mengurangi tersedianya kemampuan untuk memenuhi kebutuhan pelanggan lainnya. Dengan demikian, konsumen yang oportunis atau berperilaku oportunistik dapat memberikan dampak negatif terhadap kemampuan reverse logistic, sehingga hipotesis kedua adalah:

$\boldsymbol{H}_{2}$ : Terdapat hubungan negatif antara opportunism pelanggan dengan kemampuan reverse logistic. 
Komitmen sumber daya dalah sumber daya yang diperlukan untuk mewujudkan dan mengimplementasikan kemampuan reverse logistic. Komitmen terhadap sumber daya tersebut terdiri dari sumber daya keuangan, teknis atau teknologi dan manajerial yang nantinya akan mengarah kepada kemampuan reverse logistic. Investasi di bidang teknologi informasi dapat membantu perusahaan atau pengecer mengembangkan keunggulan kompetitif yang berkelanjutan, misalnya dengan mengembangkan kemampuan teknologi yang sulit ditiru oleh perusahaan atau pengecer lain (Day, 1994; Srinivasan et al., 2002).

Sumber daya keuangan diperlukan untuk mendanai proses strategis seperti reverse logistic. Sumber daya teknis organisasi juga dapat menciptakan kemampuan reverse logistic. Agar sumber daya yang digunakan dapat bermanfaat, maka manajemen harus mengerahkan waktu dan usahanya untuk menyediakan segala sarana yang dibutuhkan dalam mencapai tujuan perusahaan. Berdasarkan pada hal-hal tersebut, komitmen pada sumber daya dapat memberikan dampak yang positif terhadap kemampuan reverse logistic, sehingga hipotesis ketiga adalah:

$\boldsymbol{H}_{3}$ : Terdapat hubungan positif antara peningkatan komitmen sumber daya dengan kemampuan reverse logistic.

Perjanjian kontraktual adalah bagian dari proses sosialisasi dengan anggota saluran (channel) lain yang melibatkan hubungan dalam penyusunan promosi untuk mencapai tujuan (Wathne \& Heide, 2000). Peran pemerintah harus ada untuk memperkuat hubungan antara perusahaan, pengecer dan pemasok utamanya sehingga dapat mengurangi tingkat perilaku oportunistik. Salah satu metode untuk mengurangi risiko adalah dengan melaksanakan kontraktual formal yang berfungsi untuk menguraikan tujuan, tanggung jawab dan keuntungan dari hubungan mitra rantai pasok. Selain itu, kontraktual dapat berkontribusi untuk meningkatkan kinerja dalam hubungan mitra dengan meminimalkan ketidakpastian (Cannon et al., 2000). Berdasarkan manfaat yang dapat diperoleh dari diberlakukannya kontraktual, maka perjanjian kontraktual dapat bermanfaat dalam meningkatkan kemampuan reverse logistic, sehingga hipotesis keempat adalah:

$\boldsymbol{H}_{4}$ : Terdapat hubungan positif antara perjanjian kontraktual dengan kemampuan reverse logistic.

Empat anteseden (Orientasi Pelanggan, Oportunisme Pelanggan, Komitmen Sumber Daya, dan Perjanjian Kontraktual) menjadi faktor-faktor yang mempengaruhi kemampuan reverse logistic. Faktor- faktor itulah yang akan menentukan berhasil tidaknya perusahaan dalam mencapai tujuannya, yaitu penghematan biaya. Semakin baik kemampuan perusahaan dalam mengelola reverse logistic-nya, maka semakin baik pula kemampuan perusahaan dalam melakukan penghematan biaya, sehingga hipotesis kelima adalah:

$\boldsymbol{H}_{5}$ : Terdapat hubungan positif antara kemampuan reverse logistic dengan penghematan biaya reverse logistic.

Hubungan dan pengaruh anteseden terhadap kemampuan reverse logistic dalam mencapai penghematan biaya tersebut, dapat digambarkan secara konseptual dalam model analisis pada Gambar 1.

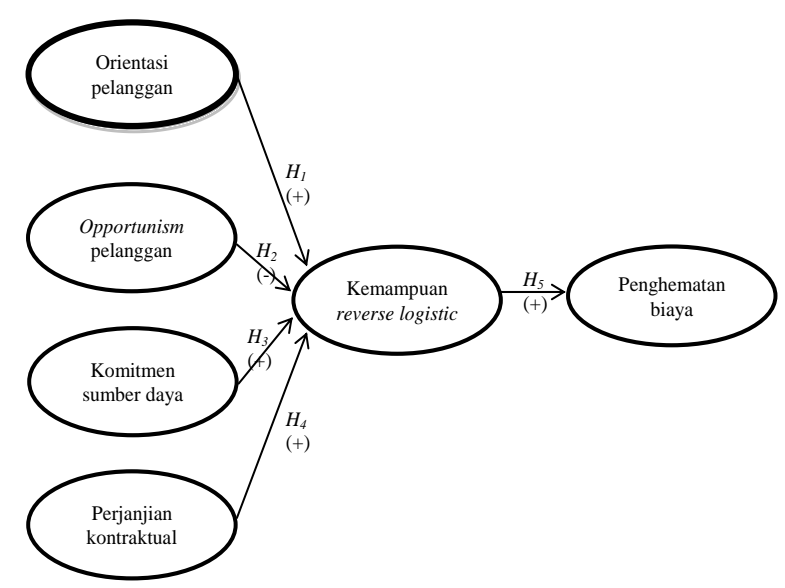

Gambar 1. Model Analisis

\section{METODE PENELITIAN}

Penelitian ini menggunakan metode kuantitatif. Penelitian kuantitatif memerlukan adanya hipotesis dan pengujiannya yang kemudian akan menentukan tahapan-tahapan berikutnya, seperti penentuan teknik analisis dan formula statistik yang akan digunakan. Pendekatan ini juga lebih memberikan makna dalam hubungannya dengan penafsiran angka statistik bukan makna secara kebahasaan dan kulturalnya. Variabel independen pada penelitian ini adalah Orientasi Pelanggan, Opportunisme Pelanggan, Komitmen Sumber Daya, dan Perjanjian Kontraktual. Variabel $Y$ atau variabel dependen dalam penelitian ini adalah Penghematan Biaya, sedangkan variabel intervening dalam penelitian ini adalah Kemampuan Reverse Logistic.

Orientasi pelanggan, merupakan sikap atau perilaku pengecer untuk memberikan kepuasan pada pelanggan. Ada lima indikator dalam faktor orientasi pelanggan yang dikembangkan dari Desphande $e t$ al. (1993) dalam penelitian yang dilakukan oleh Eric et al. (2010) antara lain yaitu: (1) produk dikembangkan 
berdasarkan informasi yang berfokus pada pelanggan; (2) memiliki pemahaman yang baik tentang bagaimana pelanggan menilai produk dan layanan; (3) lebih berfokus pada pelanggan dibandingkan pada pesaing; (4) bersaing, terutama berdasarkan diferensiasi produk yang berfokus pada permintaan pelanggan dan (5) percaya bahwa perusahaan ada untuk melayani pelanggan.

Opportunism pelanggan merupakan sebuah tindakan individu (pelanggan) atau organisasi yang menggunakan suatu hubungan, misalnya hubungan antara pembeli dan penjual untuk kepentingannya sendiri dengan mengorbankan yang lain (Williamson, 1975). Ada lima indikator dalam faktor opportunism pelanggan yang dikembangkan dari Joshi \& Arnold (1997) dalam penelitian yang dilakukan oleh Eric et al. (2010) antara lain yaitu: (1) pelanggan terkadang akan menggunakan berbagai macam cara yang diperlukan untuk memuaskan kepentingan mereka sendiri dan mengorbankan keuntungan perusahaan; (2) pelanggan terkadang membesar-besarkan tingkat kerusakan produk atau kerusakan yang disebabkan oleh perusahaan untuk mendapatkan ganti rugi; (3) pelanggan terkadang membesar-besarkan ketidakcocokan mereka terhadap kebijakan pelayanan yang baru; (4) pelanggan terkadang sedikit mengubah fakta-fakta yang ada untuk mendapatkan apa yang mereka inginkan dan (5) pelanggan terkadang berjanji untuk melakukan sesuatu tanpa benar-benar melakukannya.

Komitmen sumber daya merupakan komitmen perusahaan terhadap sumber daya untuk mencapai kemampuan reverse logistic. Sumber daya tersebut terdiri dari sumber daya keuangan, teknologi dan manajerial. Ada tiga indikator dalam faktor komitmen sumber daya menurut Eric et al. (2010) antara lain yaitu: (1) perusahaan memiliki komitmen yang besar dalam hal sumber daya keuangan untuk menangani reverse logistic; (2) perusahaan memiliki komitmen yang besar dalam hal sumber daya teknologi untuk menangani reverse logistic dan (3) perusahaan memiliki komitmen yang besar dalam hal sumber daya manajerial untuk menangani reverse logistic.

Perjanjian kontraktual merupakan bagian dari proses sosialisasi dengan anggota saluran (channel) lain yang melibatkan hubungan dalam penyusunan promosi untuk mencapai tujuan (Wathne \& Heide, 2000). Ada empat indikator dalam faktor perjanjian kontraktual menurut Eric et al. (2010) antara lain yaitu: (1) saat membahas isu-isu yang sensitif, terkadang pemasok meminta perusahaan untuk menelaah kembali perjanjian kerjasama; (2) pemasok uta-ma perusahaan selalu berpedoman pada bahasa hukum baku saat membuat perjanjian; (3) saat perusahaan membutuhkan kelonggaran terhadap per- janjian yang telah disepakati, pemasok utama tidak jarang meminta perusahaan memperhatikan kesepakatan tertulis dan (4) saat terjadi permasalahan, pemasok utama perusahaan cenderung mengikuti perjanjian tertulis formal daripada membuat kesepakatan tidak tertulis.

Kemampuan reverse logistic merupakan kemampuan internal perusahaan dalam mengelola aktivitas reverse logistic secara lebih efektif dan efisien. Ada sembilan indikator dalam faktor kemampuan reverse logistic menurut Eric et al. (2010) antara lain yaitu: (1) sistem informasi yang menangani reverse logistic perusahaan memiliki informasi yang akurat; (2) sistem informasi yang menangani reverse logistic perusahaan selalu menjamin ketersediaan informasi; (3) sistem informasi yang menangani reverse logistic perusahaan memiliki kemudahan bagi manajemen untuk mendownload informasi setiap harinya; (4) sistem informasi yang menangani reverse logistic perusahaan dirancang dengan sangat baik tanpa pengecualian di bagian-bagian tertentu; (5) sistem informasi yang menangani reverse logistic perusahaan dirancang sebaik mungkin untuk memudahkan penggunaan; (6) sistem informasi yang menangani reverse logistic perusahaan mampu menghasilkan informasi secara langsung; (7) sistem informasi yang menangani reverse logistic perusahaan mampu menghasilkan informasi yang tepat waktu; (8) sistem informasi yang menangani reverse logistic perusahaan memiliki konektivitas internal perusahaan/kompatibel dan (9) sistem informasi yang menangani reverse logistic perusahaan memiliki konektivitas eksternal perusahaan atau kompatibel.

Penghematan biaya merupakan tujuan yang ingin dicapai oleh perusahaan. Ada empat indikator dalam faktor penghematan biaya menurut Eric et al. (2010) antara lain yaitu: (1) perusahaan berhasil melakukan penghematan biaya karena melakukan kegiatan reverse logistic; (2) biaya pengeluaran yang berhubungan dengan kepatuhan terhadap aturan lingkungan hidup perusahaan lebih rendah karena penerapan metode pengembalian barang; (3) strategi perusahaan untuk menangani pengembalian barang meningkatkan posisi keuangan perusahaan menjadi relatif lebih baik dibandingkan pesaing terdekat dan (4) program reverse logistic menghemat uang kami.

Prosedur pengumpulan data yang digunakan dalam penelitian ini adalah survei lapangan untuk memperoleh data primer dengan menyebarkan kuisioner dan melakukan wawancara kepada responden yang berkecimpung langsung pada perusahaanperusahaan yang menerapkan sistem reverse logistic. Jumlah populasi yang terkait dengan penelitian ini tidak diketahui secara pasti karena tidak tersedianya 
sample frame yang menunjukan jumlah keseluruhan perusahaan baik yang berskala nasional maupun UKM untuk daerah Surabaya dan sekitarnya yang mengelola dan menerapkan proses reverse logistic. Agar sampel yang diambil dapat diuji secara statistik maka jumlah sampel minimal sesuai dengan kaidah teori batas tengah (central limit theorem) sebesar 30 responden. Penelitian ini menggunakan model analisis partial least square (PLS). Menurut Ghozali (2008), dalam penggunaan PLS, ukuran penggunaan sampel yang direkomendasikan berkisar antara 30 100 responden.

Pengujian hipotesis penelitian dilakukan dengan pendekatan Structural Equation Model (SEM) berbasis Partial Least Square (PLS). PLS adalah model persaman structural (SEM) yang berbasis komponen atau varian. Structural Equation Model (SEM) adalah salah satu bidang kajian statistik yang dapat menguji sebuah rangkaian hubungan yang relatif sulit terukur secara bersamaan. Menurut Ghozali (2006), PLS merupakan pendekatan alternatif yang bergeser dari pendekatan SEM berbasis covariance menjadi berbasis varian.

SEM yang berbasis kovarian umumnya menguji kausalitas atau teori, sedangkan PLS lebih bersifat predictive model. Teknik analisis dalam penelitian ini menggunakan teknik PLS yang dilakukan dengan dua tahap. Pertama, melakukan uji measurement model yaitu menguji validitas dan reliabilitas konstruk dari masing-masing indikator. Tahap kedua adalah melakukan uji structural model yang bertujuan untuk mengetahui ada tidaknya pengaruh antar variabel atau korelasi antara konstruk-konstruk yang diukur dengan menggunakan uji $t$ dari PLS itu sendiri.

\section{HASIL DAN PEMBAHASAN}

Bagian ini berisikan karakteristik responden dan perusahaannya serta hasil jawaban responden pada masing-masing variabel penelitian. Deskripsi karakteristik responden dan perusahaannya terdiri dari: omset rata-rata sebulan, jumlah karyawan, jenis usaha, status perusahaan, rata-rata pengembalian barang dan sektor industri. Untuk menggambarkan hasil jawaban responden, dideskripsikan variabel penelitian dengan menjelaskan nilai rata-rata pada masing-masing indikator yang membentuk variabel tersebut dan mengelompokkannya berdasarkan interval kategori jawaban.

Pada penelitian ini, variabel-variabel yang digunakan adalah merupakan faktor-faktor (anteseden) yang mempengaruhi terbentuknya suatu kemampuan reverse logistic bagi perusahaan (orientasi pelanggan, opportunism pelanggan, komitmen sumber daya, dan perjanjian kontraktual). Keempat variabel tersebut mempengaruhi kemampuan perusahaan dalam mengelola reverse logistic-nya sehingga dapat mencapai tujuan penghematan biaya. Skala yang digunakan adalah likert scale yaitu skala peringkat yang dimulai dari nilai 1 sebagai bobot terendah sampai dengan nilai 7 sebagai bobot tertinggi.

Nilai rata-rata dari masing-masing partisipan terhadap item-item pernyataan ditentukan dengan cara menjumlahkan nilai jawaban tersebut dibagi dengan masing-masing jumlah item atau indikator dalam setiap variabel. Standar deviasi yang merupakan hasil penghitungan SPSS18 juga akan ditampilkan untuk melihat besarnya sebaran data.

\section{Corrected Item-Total Correlation}

Menurut Azwar (2012), suatu item dikatakan valid apabila nilai koefisiennya $>0,3$. Untuk mengetahui validitas item, dapat dilihat pada corrected itemtotal correlation yang merupakan output dari SPSS. Tabel 1 menyatakan hasil corrected item-total correlation pada tiap variabel.

Tabel 1. Validity dan Reliability Semua Indikator

\begin{tabular}{cccc}
\hline Indikator & Validitas & Reliabiltitas & Keterangan \\
\hline ORP2 & 0,502 & 0,736 & Valid dan reliabel \\
ORP4 & 0,793 & & \\
ORP5 & 0,433 & & \\
\hline OPP2 & 0,717 & 0,837 & Valid dan reliabel \\
OPP3 & 0,631 & & \\
OPP4 & 0,764 & & \\
\hline KSD1 & 0,725 & 0,832 & Valid dan reliabel \\
KSD2 & 0,670 & & \\
KSD3 & 0,729 & & \\
\hline PK1 & 0,588 & 0,771 & Valid dan reliabel \\
PK2 & 0,633 & & \\
PK3 & 0,642 & & \\
PK4 & 0,435 & & \\
\hline KRL1 & 0,655 & 0,909 & Valid dan reliabel \\
KRL2 & 0,763 & & \\
KRL3 & 0,720 & & \\
KRL4 & 0,866 & & \\
KRL5 & 0,792 & & \\
KRL6 & 0,836 & & \\
KRL7 & 0,803 & & \\
KRL8 & 0,545 & & \\
KRL9 & 0,473 & & \\
\hline PB1 & 0,783 & 0,861 & Valid dan reliabel \\
PB2 & 0,592 & & \\
PB3 & 0,664 & & \\
PB4 & 0,820 & & \\
\hline
\end{tabular}

\section{Analisis Model dan Pengujian Hipotesis}

Analisis model dan pengujian hipotesis dalam penelitian ini menggunakan teknik PLS yang di 
dalamnya terdapat uji measurement model, yaitu validitas indikator konstruk dan reliabilitas indikator konstruk serta uji structural model, yaitu melihat korelasi antara konstruk-konstruk yang diukur yang merupakan uji $t$ dari partial least square itu sendiri.

\section{Pengujian Measurement (Outer) Model}

Outer model mendefinisikan bagaimana setiap indikator berhubungan dengan variabel latennya (Ghozali, 2008). Pada penelitian ini, outer model diinterpretasikan berdasarkan nilai convergent validity, cronbach alpha dan composite reliability.

1. Convergent Validity

Prosedur pengujian convergent validity adalah dengan mengkorelasikan skor item (component score) dengan construct score yang kemudian menghasilkan nilai factor loading. Nilai factor loading dikatakan tinggi jika komponen atau indikator berkorelasi lebih dari 0,70 dengan konstruk yang ingin diukur, namun untuk penelitian tahap awal dari pengembangan, factor loading 0,5 sampai 0,6 dianggap cukup (Chin, 1998; Ghozali, 2008). Outer loading dilakukan dengan dua tahap untuk mengeluarkan indikator yang tidak valid (factor loading di bawah 0,5). Indikator-indikator yang diangggap sudah valid dan mampu mengukur semua dimensi secara akurat tersebut adalah OPP2, OPP3, OPP4, ORP2, ORP4, ORP5, KSD1, KSD2, KSD3, PK1, PK2, PK3, PK4,
KRL1, KRL2, KRL3, KRL4, KRL5, KRL6, KRL7, PB1, PB2, PB4.

2. Discriminant Validity

Discriminant validity digunakan untuk menguji apakah indikator-indikator suatu konstruk tidak berkorelasi tinggi dengan indikator dari konstruk lain atau paling tidak indikator-indikator tersebut berkorelasi lebih rendah dengan indikator-indikator konstruk yang lain (Garson, 2002). Untuk melihat korelasi antar indikator tersebut, berikut adalah hasil cross loading yang merupakan output dari SmartPLS:

Berdasarkan tabel di atas, dapat diketahui bahwa semua indikator (yang bercetak tebal) mempunyai loading yang lebih besar daripada indikator lainnya. Hal ini menunjukan bahwa indikator-indikator tersebut tidak berkorelasi tinggi dengan indikator dari konstruk lain. Dengan demikian, uji validitas diskriminannya dapat diterima.

3. Cronbach Alpha dan Composite Reliability

Untuk mengukur tingkat reliabilitas variabel penelitian, maka digunakan koefisien alfa atau cronbach alpha. Item pengukuran dikatakan reliabel jika memiliki nilai koefisien alfa lebih besar dari 0,7 (Ghozali, 2008). Berikut adalah tabel yang menunjukan nilai cronbach alpha:

Berdasarkan Tabel 3, semua nilai cronbach alpha di atas 0,7. Hal ini menunjukan bahwa keenam dimensi tersebut memenuhi standar minimal cronbach alpha, namun meskipun jika nilai cronbach

Tabel 2. Cross Loading Antar Indikator

\begin{tabular}{ccccccc}
\hline & $\begin{array}{c}\text { Kemampuan } \\
\text { reverse logistic }\end{array}$ & $\begin{array}{c}\text { Komitmen } \\
\text { sumber daya }\end{array}$ & $\begin{array}{c}\text { Opportunisme } \\
\text { pelanggan }\end{array}$ & $\begin{array}{c}\text { Orientasi } \\
\text { pelanggan }\end{array}$ & $\begin{array}{c}\text { Pengehematan } \\
\text { biaya }\end{array}$ & $\begin{array}{c}\text { Perjanjian } \\
\text { kontraktual }\end{array}$ \\
\hline KRL1 & 0,8354 & 0,6500 & $-0,2004$ & $-0,2797$ & $-0,0242$ & 0,1318 \\
KRL2 & 0,9078 & 0,6749 & $-0,3181$ & $-0,2351$ & $-0,1084$ & 0,2943 \\
KRL3 & 0,8256 & 0,6611 & $-0,0512$ & $-0,1233$ & $-0,1189$ & 0,1509 \\
KRL4 & 0,8883 & 0,6714 & $-0,2670$ & $-0,1159$ & $-0,3247$ & 0,5470 \\
KRL5 & 0,8818 & 0,6985 & $-0,1293$ & $-0,2197$ & $-0,0274$ & 0,4641 \\
KRL6 & 0,9350 & 0,6951 & $-0,0861$ & $-0,0569$ & $-0,1209$ & 0,4838 \\
KRL7 & 0,8734 & 0,5112 & $-0,0449$ & $-0,0768$ & $-0,2424$ & 0,3967 \\
KSD1 & 0,6209 & 0,8753 & $-0,2274$ & $-0,1158$ & 0,1557 & 0,3951 \\
KSD2 & 0,6587 & 0,8559 & $-0,0893$ & $-0,0763$ & 0,0454 & 0,3683 \\
KSD3 & 0,6686 & 0,8841 & $-0,0572$ & $-0,1825$ & 0,0157 & 0,3618 \\
OPP2 & $-0,0409$ & $-0,1298$ & 0,7385 & 0,0064 & 0,1114 & $-0,2560$ \\
OPP3 & $-0,2145$ & $-0,1310$ & 0,9417 & 0,2263 & 0,0345 & $-0,0027$ \\
OPP4 & $-0,1084$ & $-0,1097$ & 0,8369 & 0,1744 & 0,0859 & $-0,2118$ \\
ORP2 & $-0,0932$ & $-0,0537$ & 0,1712 & 0,7477 & 0,1928 & $-0,0406$ \\
ORP4 & $-0,2048$ & $-0,1768$ & 0,1302 & 0,9636 & 0,2011 & 0,0797 \\
ORP5 & $-0,0993$ & $-0,0710$ & 0,2795 & 0,6914 & 0,1470 & 0,3268 \\
PB1 & $-0,1638$ & 0,1305 & 0,0844 & 0,1583 & 0,8977 & 0,0526 \\
PB2 & $-0,1387$ & 0,0085 & 0,0495 & 0,2173 & 0,8264 & $-0,0851$ \\
PB4 & $-0,0848$ & 0,0544 & 0,0173 & 0,2108 & 0,8829 & $-0,1024$ \\
PK1 & 0,3090 & 0,3741 & 0,0067 & $-0,1125$ & $-0,2938$ & 0,8007 \\
PK2 & 0,1993 & 0,2459 & $-0,0163$ & 0,3551 & 0,0836 & 0,7278 \\
PK3 & 0,3083 & 0,3247 & $-0,1134$ & 0,5807 & 0,1350 & 0,7654 \\
PK4 & 0,3816 & 0,3385 & $-0,1583$ & $-0,2417$ & 0,0004 & 0,7552 \\
\hline
\end{tabular}


alpha tidak memenuhi standar minimal, suatu variabel bisa dianggap reliabel jika nilai composite reliability-nya di atas 0,7 (Ghozali, 2008). Hal tersebut dikarenakan composite reliability lebih akurat daripada nilai cronbach alpha. Berikut adalah composite reliability yang menunjukan bahwa semua variabel dan dimensi adalah reliabel.

Tabel 3. Cronbachs Alpha

\begin{tabular}{lc}
\hline & Cronbachs Alpha \\
\hline Kemampuan reverse logistic & 0,950623 \\
Komitmen sumber daya & 0,842157 \\
Opportunism pelanggan & 0,837343 \\
Orientasi pelanggan & 0,732253 \\
Penghematan biaya & 0,842056 \\
Perjanjian kontraktual & 0,767801 \\
\hline
\end{tabular}

Tabel 4. Composite Reliablity

\begin{tabular}{lc}
\hline & Composite Reliability \\
\hline Kemampuan reverse logistic & 0,9596 \\
Komitmen sumber daya & 0,9048 \\
Opportunism pelanggan & 0,8796 \\
Orientasi pelanggan & 0,8480 \\
Penghematan biaya & 0,9028 \\
Perjanjian kontraktual & 0,8475 \\
\hline
\end{tabular}

Berdasarkan tabel composite reliability, dapat diketahui bahwa semua dimensi dan variabel memenuhi standar reliabilitas karena memiliki nilai composite reliability di atas 0,7 . Hal ini menunjukan bahwa semua variabel memiliki keandalan yang cukup tinggi untuk melakukan fungsi yang diinginkan sepanjang suatu periode waktu tertentu.

\section{Pengujian Structural (Inner) Model}

Tujuan dari uji structural model adalah melihat korelasi antara konstruk-kontruk yang diukur yang merupakan uji $t$ dari partial least square itu sendiri. Structural/inner model dapat diukur dengan dua cara yaitu:

\section{R-Square Model}

Dalam menilai model dengan PLS dimulai dengan melihat $R$-Square untuk setiap variabel laten dependen. Perubahan nilai $R$-Square dapat digunakan untuk menilai pengaruh variabel laten independen tertentu terhadap variabel laten dependen apakah mempunyai pengaruh yang substantif. Tabel 5 merupakan hasil estimasi $R$-square dengan menggunakan SmartPLS.

Tabel 5. $R$-Square

\begin{tabular}{cc}
\hline & $\boldsymbol{R}$-Square \\
\hline KRL & 0,578612 \\
PB & 0,025033 \\
\hline
\end{tabular}

Berdasarkan $R$-Square di atas diketahui bah-wa konstruk KRL sebesar 0,578612 dan konstruk PB sebesar 0,025033 . Semakin tinggi $R$-Square, maka semakin besar variabel independen tersebut dapat menjelaskan variabel dependen sehingga semakin baik persaman strukturalnya. Variabel KRL memiliki nilai $R$-Square sebesar 0,578612 yang berarti $57,8 \%$ variabel KRL dijelaskan oleh variabel KSD, OPP, ORP, PK, sedangkan sisanya dijelaskan oleh variabel lain yang tidak diteliti. Variabel PB memiliki $R$-Square sebesar 0,025033 yang berarti $2,5 \%$ variabel PB dijelaskan oleh variabel KRL, sedangkan sisanya dijelaskan oleh variabel-variabel lainnya.

\section{Pengujian Validitas Model Keseluruhan (Outer dan Inner Model)}

Untuk memvalidasi model secara keseluruhan, maka digunakan goodness of fit $(\mathrm{GoF})$ yang diperkenalkan oleh Tenenhaus dkk. (2004). GoF index ini merupakan ukuran tunggal yang digunakan untuk memvalidasi performa gabungan antara model pengukuran (outer model) dan model struktural (inner model). Nilai GoF index diperoleh dari average communalities index dikalikan dengan nilai $R$-Square model. Menurut Tenenhaus et al. (2004) nilai $G o F$ terbentang antara $0-1$ de-ngan interpretasi 0,1 (GoF kecil); 0,25 (GoF moderat) dan 0,36 ( $G o F$ besar). Rata-rata dari communalities model dan rata-rata $R$-Square yang diolah dengan menggunakan SmartPLS dapat dilihat pada Tabel 6 dan Tabel 7.

Tabel 6. Hasil Rata-Rata Communalities

\begin{tabular}{cc}
\hline & Communality \\
\hline KRL & 0,7724 \\
KSD & 0,7600 \\
OPP & 0,7108 \\
ORP & 0,6552 \\
PB & 0,7561 \\
PK & 0,5817 \\
\hline Rata-Rata Communality & 0,7061 \\
\hline
\end{tabular}

Tabel 7. Hasil Rata-Rata $R$-Square

\begin{tabular}{cc}
\hline & $\boldsymbol{R}$ Square \\
\hline KRL & 0,5786 \\
KSD & \\
OPP & \\
ORP & \\
PB & 0,0250 \\
PK & \\
\hline Rata-Rata $R$-Square & 0,3018 \\
\hline
\end{tabular}

Berdasarkan perhitungan, diperoleh nilai rata-rata communalities adalah 0,7061 , sedangkan nilai rata-rata $R$ Square adalah 0,3018 , sehingga: $G o F=\sqrt{ } 0,7061 \times 0,3018=0,2536$ (GoF moderat $)$ 
Dari hasil tersebut bisa disimpulkan bahwa performa antara model pengukuran dan model struktural memiliki GoF moderat yaitu sebesar 0,2536 (di atas 0,25). Hal ini menandakan bahwa performa gabungan dari model pengukuran dan model struktural tidak terlalu besar (moderat).

\section{Estimasi Koefisien Jalur}

Pada tahap ini akan dilihat nilai estimasi untuk hubungan jalur dalam model structural yang diperoleh dengan prosedur bootstrapping. Nilai yang dianggap signifikan adalah jika nilai $t$ statistik lebih besar dari 1,96 untuk masing-masing hubungan jalurnya. Untuk melihat arah hubungan antar variabel, digunakan nilai original sample sebagai parameternya. Jika original sample menunjukkan angka yang bernilai positif, maka hubungan yang terjadi antara variabel tersebut adalah positif.

\section{Pengujian Hipotesis}

Langkah selanjutnya adalah pengujian hipotesis dan hubungan jalur antar logistik tersebut yang akan menjawab hipotesis pada penelitian ini. Berikut adalah Tabel 8 path coefficient berikut ini yang merupakan hasil uji bootstrapping.

Terdapat pengaruh negatif pada variabel kemampuan reverse logistic (KRL) terhadap variabel penghematan biaya (PB). Hasil perhitungan terhadap koefisien parameter antara KRL dan PB menunjukkan adanya pengaruh negatif $(-0,158217)$ dengan nilai $T$ statistik 2,34>1,96. Dengan hasil seperti ini, maka hipotesis penelitian $H_{5}$ ditolak atau bisa dikatakan tidak didukung oleh data empiris. Terdapat pengaruh positif pada variabel komitmen sumber daya (KSD) terhadap variabel KRL.

Hasil perhitungan terhadap koefisien parameter antara KSD dan KRL menunjukkan adanya pengaruh positif $(0,669731)$ dengan nilai $T$ statistik 9,34 > 1,96. Dengan hasil seperti ini, maka hipotesis penelitian $\mathrm{H}_{3}$ diterima atau bisa dikatakan didukung oleh data empiris. Selain itu, terdapat juga temuan adanya pengaruh negatif pada variabel opportunism pelanggan (OPP) terhadap variabel KRL. Hasil perhitungan terhadap koefisien parameter antara OPP dan KRL menunjukkan adanya pengaruh negatif $(-0,057976)$ dengan nilai $T$ statistik $0,86<1,96$. Dengan hasil seperti ini, maka hipotesis penelitian $\mathrm{H}_{2}$ ditolak atau bisa dikatakan tidak didukung oleh data empiris.

Terdapat pengaruh negatif pada variabel orientasi pelanggan (ORP) terhadap variabel KRL. Hasil perhitungan terhadap koefisien parameter antara ORP dan KRL menunjukkan adanya pengaruh negatif (-0,088916) dengan nilai $T$ statistik 2,31 > 1,96. Dengan hasil seperti ini, maka hipotesis penelitian $H_{I}$ ditolak atau bisa dikatakan tidak didukung oleh data empiris. Terdapat pengaruh positif pada variabel perjanjian kontraktual (PK) terhadap variabel KRL. Hasil perhitungan terhadap koefisien parameter antara PK dan KRL menunjukkan adanya pengaruh positif $(0,128069)$ dengan nilai $T$ statistik 2,06 > 1,96. Dengan hasil seperti ini, maka hipotesis penelitian $H_{4}$ diterima atau bisa dikatakan didukung oleh data empiris.

\section{Diskusi dan Pembahasan}

Hasil uji hipotesis menunjukkan bahwa penguatan kemampuan reverse logistic masih dipandang sebagai cost center daripada sebagai suatu alat untuk mencapai keunggulan bersaing. Hanya dua dari empat anteseden yang terbukti secara empiris mampu menjadi faktor prediktor Kemampuan Reverse Logistic. Dua anteseden tersebut adalah Perjanjian Kontraktualdan Komitmen Sumber Daya. Dapat bahwa perusahaan-perusahaan yang terlibat di dalam penelitian ini melakukan penguatan terhadap kemampuan reverse logistic-nya sebatas sebagai pemenuhan kewajiban seperti yang ditetapkan dalam surat perjanjian dengan rekan mereka, sedangkan sisi front end pelayanan, yaitu Komitmen terhadap Pelanggan bukan menjadi pemicu penguatan kemampuan reverse logistic.

Tabel 8. Path Coefficient dan T-Statistics

\begin{tabular}{|c|c|c|c|c|c|}
\hline & $\begin{array}{l}\text { Original } \\
\text { Sample }\end{array}$ & $\begin{array}{l}\text { Sample Mean } \\
\text { (M) }\end{array}$ & $\begin{array}{l}\text { Standard } \\
\text { Deviation }\end{array}$ & $\begin{array}{l}\text { Standard } \\
\text { Error }\end{array}$ & $\begin{array}{c}\text { T Statistics } \\
(|O / S T E R R|)\end{array}$ \\
\hline $\begin{array}{l}\text { Kemampuan reverse logistic -> } \\
\text { Penghematan biaya. }\end{array}$ & $-0,158217$ & $-0,177615$ & 0,067580 & 0,067580 & 2,341177 \\
\hline $\begin{array}{l}\text { Komitmen sumber daya -> Kemampuan } \\
\text { reverse logistic }\end{array}$ & 0,669731 & 0,655008 & 0,071699 & 0,071699 & 9,340803 \\
\hline $\begin{array}{l}\text { Opportunism pelanggan -> Kemampuan } \\
\text { reverse logistic }\end{array}$ & $-0,057976$ & $-0,095726$ & 0,067172 & 0,067172 & 0,863097 \\
\hline $\begin{array}{l}\text { Orientasi pelanggan -> Kemampuan } \\
\text { reverse logistic }\end{array}$ & $-0,088916$ & $-0,084211$ & 0,038518 & 0,038518 & 2,308465 \\
\hline $\begin{array}{l}\text { Perjanjian kontraktual-> Kemampuan } \\
\text { reverse logistic }\end{array}$ & 0,128069 & 0,155115 & 0,061947 & 0,061947 & 2,067405 \\
\hline
\end{tabular}


Temuan ini seirama dengan ditolaknya hipotesis kelima, yang menguji hubungan antara Kemampuan Reverse Logistic dengan Penghematan Biaya. Hipotesis ini ditolak, karena hubungan yang diajukan bernilai positif, sementara uji hipotesis menunjukkan hasil sebaliknya. Hal ini menunjukkan bahwa semakin kuat kemampuan reverse logistic pada perusahaan-perusahaan yang menjadi sampel penelitian, maka menyebabkan meningkatkan biaya. Temuan ini mempertegas asumsi yang disampaikan, bahwa reverse logistic masih dipandang sebagai tanggung jawab dan tugas, belum dijadikan alat meraih keunggulan berkompetisi.

Hal ini tentu menjadi anomali, jika dibandingkan dengan temuan penelitian yang telah dilakukan dengan setting perusahaan-perusahaan di negaranegara maju yang telah melihat peningkatan kemampuan reverse logistic sebagai alat untuk menciptakan kepuasan konsumen. Mereka memandang kepuasan konsumen yang prima akan membuat bisnis berjalan lebih sustainable. Pengelolaan reverse logistic yang baik di-setting perusahaan-perusahaan barat juga me-nunjukkan adanya penghematan biaya yang signifikan. Hal ini menjadi tantangan sekaligus peluang bagi perusahaan-perusahaan Nasional untuk mampu melakukan efisiensi aliran reverse logistic mereka.

Kontribusi lain dari penelitian ini ditunjukkan oleh peran mediasi pada kemampuan reverse logistic dalam penghematan biaya. Elemen komitmen sumber daya, perjanjian kontraktualdan kemampuan reverse logistic dapat mewujudkan penghematan biaya yang lebih tinggi melalui unsur-unsur seperti biaya pengeluaran yang berhubungan dengan kepatuhan terhadap aturan lingkungan hidup, meningkatkan daya saing dan efisiensi dalam memenuhi kebutuhan pelanggan. Temuan ini didukung oleh penelitian yang dilakukan oleh Eric et al. (2010).

Berdasarkan diskusi dan pembahasan di atas, penulis mengajukan beberapa saran untuk perusahaan dan akademisi sebagai berikut: untuk perusahaan dan pengecer agar lebih memperhatikan dan meningkatkan lagi kemampuan reverse logistic, terutama dalam hal orientasi pelanggan dan penanganan masalah opportunisme pelanggan, karena dua faktor tersebut berpengaruh negatif terhadap kemampuan reverse logistic. Solusi yang tepat dalam menangani kedua hal tersebut seperti menjalin hubungan yang baik dengan pelanggan akan meningkatkan kemampuan reverse logistic sehingga dapat menghemat biaya perusahaan. Meskipun bersifat pasif, penguatan kemampuan reverse logistic juga bisa dilakukan dengan meningkatkan komitmen terhadap sumber daya yang dimilikinya dan memperbarui perjanjian-perjanjian dalam kontraktual, sehingga kemampuan dalam mengelola reverse logistic dapat lebih baik lagi.

\section{SIMPULAN DAN SARAN}

Penelitian ini telah menghasilkan temuan yang mengkonfirmasi teori yang diajukan oleh Eric et al. (2010), bahwa anteseden orientasi pelanggan menunjukkan pengaruh yang tidak signifikan meskipun ada kecenderungan memiliki pengaruh negatif terhadap kemampuan reverse logistic dan anteseden opportunisme pelanggan menunjukkan pengaruh negatif yang tidak signifikan terhadap kemampuan reverse logistic perusahaan dan pengecer. Dalam penelitian ini juga ditemukan adanya hubungan negatif dan signifikan pada kemampuan reverse logistic terhadap penghematan biaya. Oleh karena itu, hendaknya akademisi menjadikan penelitian ini sebagai salah satu acuan untuk memperkaya literatur dalam penelitian selanjutnya dalam konteks pengelolaan reverse logistic yang efektif dan efisien.

Demi kebaikan pada penelitian selanjutnya, diusulkan beberapa saran untuk penelitian selanjutnya dalam konteks anteseden yang mempengaruhi reverse logistic dan dampaknya terhadap penghematan biaya. Saran pertama, sebaiknya peneliti menambah jumlah responden untuk memperkuat generalisasi hasil dari temuan yang dilakukan. Meskipun berdasarkan central limit theorm dan aturan penggunaan PLS bahwa batas minimal responden sebanyak 30, namun dengan jumlah responden yang lebih banyak akan menambah kekuatan uji penelitian tersebut.

Saran kedua, sebaiknya diuji peranan Kontrol terhadap Kualitas (Quality Control) untuk mengetahui bagaimana sistem pengelolaan reverse logistic di perusahaan sehingga dapat dilakukan perbaikan secara berkelanjutan. Diduga, semakin baik mekanisme Quality Control dalam perusahaan, semakin baik pula pengelolaan reverse logistic di perusahaan tersebut. Saran terakhir, sebaiknya melakukan pengujian hipotesis untuk model yang sama tetapi pada dua setting industri yang berbeda, yaitu manufaktur dan sektor jasa untuk mengetahui keunikan masingmasing jenis bisnis tersebut.

Penelitian ini juga tidak terlepas dari kelemahan klasik yang dihadapi oleh jenis penelitian kuantitatif dengan pengujian hipotesis secara statistik, yaitu ketidakmampuan dalam menjelaskan faktor "mengapa" terjadinya fenomena yang tertangkap dalam penelitian. Oleh karena itu, untuk melengkapi pemahaman kita tentang antiseden yang membentuk kemampuan reverse logistic, diperlukan desain penelitian kualitatif. Penelitian ini bisa dijadikan salah satu acuan awal dalam membedah alasan perusahaanperusahaan yang menjadi responden lebih mengutamakan peningkatan kemampuan reverse logistic sebagai pemenuhan kewajiban, alih-alih sebagai alat untuk mencapai keunggulan bersaing. Beberapa teori memiliki potensi kuat sebagai dasar analisis, salah satunya adalah Total Cost Economy. 


\section{DAFTAR REFERENSI}

Azwar, S. 2012. Reliabilitas dan Validitas. Edisi 4. Yogyakarta: Pustaka Pelajar.

Bernon, M., Cullen. J., \& Rowat, C. 2004. The Efficiency of Reverse Logistics. Working Paper, Cranfield University, UK.

Bowersox, D. J. 1990. The Strategic Benefits of Logistics Alliances. Harvard Business Review, 68 (2): 36-45.

Cannon, J. P., Achrol, R. S., \& Gundlach, G. T. 2000. Contracts, Norms, and Plural Form Governance. Journal of the Academy of Marketing Science, 28(2): 180-195.

Chin. 1998. The Partial Least Square Approach for Structural Equation Modelling. New Jersey: Marwah.

Daugherty, P. J., Richey, R. G., Genchev, S. E., \& Chen, H. 2005. Reverse Logistics: Superior Performance Through Focused Resource Commitments to Information Technology. Transportation Research, 41(2): 77-92.

Day, G. S. 1994. The Capabilities of Market-Driven Organizations. Journal of Marketing, 58(4): 3753.

De Brito, M. P., Flapper, S. D. P., \& Dekker, R. 2002. Reverse Logistics: A Review of Case Studies. Econometric Institute Report EI, 21: 1-31.

Deshpande, R., Farley, J. U., \& Webster, F. E. 1993. Corporate Culture, Customer Orientation and Innovativeness in Japanese Firms: A Quadrad Analysis. Journal of Marketing, 57(1): 23-37.

Eric P. J., Thomas L. P., \& Luren, S. 2010. Reverse Logistics Capabilities: Antecedent and Cost Savings. International Journal of Physical Distribution and Logistics Management, 40(3): 228-246.

Fleischmann, M., Jacqueline, M., Van der Laan, E., Van Nunen, J. A. E. E., \& Van Wassenhove, L. N. 1997. Quantitative Models for Reverse Logistics: A Review. European Journal of Operational Research, 103(1): 1-17.

Francas, D. \& Minner, S. 2009. Manufacturing Network Configuration in Supply Chains with Product Recovery. Omega, 37(4): 757-769.

Garson, D. 2002. Differential Bias in Representing Model Parameters? Multivariate Behavior Research, 28(3): 263-311.

Ghozali, I. 2006. Structural Equation Modelling: Metode Alternatif dengan PLS. Semarang: Badan Penerbit Universitas Diponegoro. . 2008. Structural Equation Modelling: Metode Alternatif dengan Partial Least Square $(P L S)$. Edisi Kedua. Semarang: Universitas Diponegoro.
Guide, Jr. V. D. R., Jayaraman, V., Srivastava, R. \& Benton, W. C. 2000. Supply Chain Management for Recoverable Manufacturing Systems. Sustainable Business, 30(3): 125-142.

Horvath, P. A., Autry, C. W., \& Wilcox, W. E. 2005. Liquidity Implications of Reverse Logistics for Retailers. Journal of Retailing, 81(3): 191-205.

Jayaraman, V. \& Luo, Y. 2006. Creating Competitive Advantages through New Value Creation: A Reverse Logistics Perspective. Academy of Management Perspectives, 20(1): 56-73.

Krikke, H. 1998. Recovery Strategies and Reverse Logistic Network Design. Ph.D. Thesis. Netherlands: University of Twente.

Larson, P. D., Poist, R. F., \& Halldorsson, A. 2007. Perspective on Logistics vs Supply Chain: A Survey of SCM Professionals. Journal of Business Logistics, 28(1): 1-24.

Petersen, A. J. \& Kumar, V. 2009. Are Product Returns a Necessary Evil? Antecedents and Consequences. Journal of Marketing, 73(5): 3551.

Richey, R. G., Chen, H., Genchev, S. E., \& Daugherty, P. J. 2005. Developing Effective Reverse Logistics Programs. Journal of Marketing, 57 (1): 23-38.

Rivera, R. \& Ertel, J. 2009. Reverse Logistics Network Design for the Collection of End-ofLife Vehicles in Mexico. European Journal of Operational Research, 196(3): 930-939.

Rogers, D. S. \& Tibben-Lembke, R. 1999. Going Backwards: Reverse Logistics Trends and Practices. Pittsburgh: RLEC Press. . 2001. An Examination of Reverse Logistics Practices. Journal of Business Logistics, 22(2): 129-146.

Schulman, J. D., Coughlan, A. T., \& Savaskan, R. C. 2006. Optimal Reverse Channel Structure for Consumer Product Returns. Marketing Science, 29(6): 1071-1085.

Srinivasan, R., Lilien, G. L., \& Rangaswamy, A. 2002. Technological Opportunism and Radical Technology Adoption: An Application to EBusiness. Journal of Marketing, 66(3): 47-61.

Stock, J. R. 2001. The Seven Deadly Sins of Reverse Logistics. Material Handling Management, 56(3): 5-11.

Stock, J. \& Mulki, J. P. 2009. Product Returns Processing: An Examination of Practices of Manufacturers, Wholesalers/ Distributors and Retailers. Journal of Business Logistics, 30(1): 33-63.

Stock, J., Speh, T., \& Shear, H. 2002. Many Happy (Products) Returns. Harvard Business Review, 80(7): 16-17. 
2006. Managing Product Returns for Competitive Advantage. MIT Sloan Management Review, 48(1): 57-62.

Tenenhaus, M., Squillacciotti, S., Trinchera, L., \& Vinzi, V. E. 2004. REBUS-PLS: A Responsebased Procedure for Detecting Unit Segments in PLS Path Modelling. Applied Stochastic Models in Business and Industry, 24 (5): 439-458.

Trebilcock, B. 2001. Why Are Return so Tough? Modern Materials Handling, 56(11): 45-51.
Wathne, K. H. \& Heide, J. B. 2000. Opportunism in Interfirm Relationships: Forms, Outcomes and Solutions. Journal of Marketing, 64(4): 36-51.

Williams, M. 2007. Building Genuine Trust Through Interpersonal Emotion Management: A Threat Regulation Model of Trust and Collaboration Across Boundaries. Academy of Management Review, 32(2): 595-621.

Williamson, O. E. 1975. Markets and Hierarchies: Analysis and Antitrust Implications. New York: The Free Press. 